\title{
Rated graphic distinctiveness of consonants
}

\author{
EDWARD J. PAVUR, JR. and DONALD H. KALSLER \\ University of Missouri, Columbia, Missouri 65201
}

\begin{abstract}
Mean ratings of graphic distinctiveness were obtained for pairs of consonants. The comparisons were between uppercase forms of different consonants, lowercase forms of different consonants, and uppercase vs lowercase forms of the same consonants. The ratings were demonstrated to have satisfactory reliability and to covary moderately well with feature-component measures of letter-pair distinctiveness.
\end{abstract}

The present study presents normative data for the graphic distinctiveness of pairs of consonants. Specifically, ratings of graphic distinctiveness were obtained for all combinations of paired consonants in both their uppercase and lowercase forms, together with comparisons between the uppercase and lowercase forms of each consonant. The norms supplement Gibson's (1969) feature-component system of measuring letter-pair distinctiveness, a system based on the percentage of physical features shared by letters. However, Gibson's system is applicable only to uppercase comparisons. Moreover, gradations of distinctiveness are somewhat limited by the relatively few physical features employed.

Letters obviously vary in the extent of their distinctiveness. Variation in distinctiveness, in turn, is likely to be related to performance on tasks requiring discriminations between letters, whether the letters occur as individual items or as elements of words serving as items. These tasks include letter identification (e.g., Thompson \& Massaro, 1973), same-different letter judgments (e.g., Krueger, 1973), and recognition learning (e.g., Kausler \& Pavur, in press), and they. involve discriminations between both nominally different letters (e.g., B vs P) and nominally identical letters (e.g., B vs b). The present norms should facilitate such research by extending the material available for selecting consonant pairs of differential distinctiveness.

\section{METHOD}

\section{Subjects and Design}

The Ss were 114 students in undergraduate psychology courses, primarily general psychology. Each S rated 210 letter-pair comparisons for graphic distinctiveness-the 20 uppercase-lowercase comparisons between nominally identical consonants (e.g., B, b), 95 of the 190 uppercase comparisons between nominally different consonants (e.g., B, P), and 95 of the 190 lowercase comparisons between nominally different consonants (e.g., g q). A given $\mathrm{S}$ received all 190 comparisons between nominally different consonants, half of them in uppercase form and the other halt in lowercase form. N was 114 for nominally identical comparisons, approximately 57 for nominally different uppercisc comparisons, and approximately 57 for nominally different lowerasse comparisons.

\section{Procedure}

Test booklets were typed on an IBM 2741 communications terminal with a standard pica type ball. The use of only one typeface necessarily restricts the generalization of the present norms. However, it seems unlikely that the graphic content of the present set of consonants differs markedly from that of the consonants serving as task components in most research studies.

The cover sheet of each test booklet contained instructions for rating each letter pair on a 9-point scale, with 1 indicating high dissimilarity of a pair's graphic content (i.e., high distinctiveness) and 9 indicating high similarity (i.e., low distinctiveness). The instructions were patterned after those employed by Zechmeister (1969) to measure the graphic distinctiveness of individual words. However, they were modified in accordance with the present task requirements. Examples of vowels varying in graphic distinctiveness were given for illustrative purposes. Two alternate forms of the booklet, I and II, were used approximately equally often. The forms differed in the left-right spatial order of intrapair elements. For any given pair, one element appeared on the spatial left in one form and on the spatial right in the other form (e.g., B, P in Form $I$ and $P, B$ in Form II). In addition, four different random orders of pairs were employed for each form.

\section{RESULTS AND DISCUSSION}

Mean ratings and standard deviations for the 380 comparisons between nominally different consonants are given in Table 1 (190 uppercase and 190 lowercase comparisons, all ratings pooled over form and order variants). The range of mean ratings was $1.95-8.03$ for uppercase forms and 1.50-8.26 for lowercase forms. To aid in the selection of letter pairs varying in distinctiveness, the ranks of the comparisons (from most to least distinctive) within their specific case distribution are also given in Table 1. Mean ratings and standard deviations for the 20 comparisons (uppercase vs lowercase) between nominally identical consonants are given in Table 2 (again pooled over form and order variants). Also given in this table are the rankings from most to least distinctive.

To estimate reliabilities of the present norms, two separate scores were found initially for each letter-pair comparison. viz, the mean rating on Form I and the mean rating on Form II (e.g., B, P and $\mathrm{P}, \mathrm{B} ; \mathrm{b}, \mathrm{B}$ and $B, b)$. For each of the three kinds of letter-pair 
Table 1

Ratings of Graphic Distinctiveness for Pairs of Different Consonants

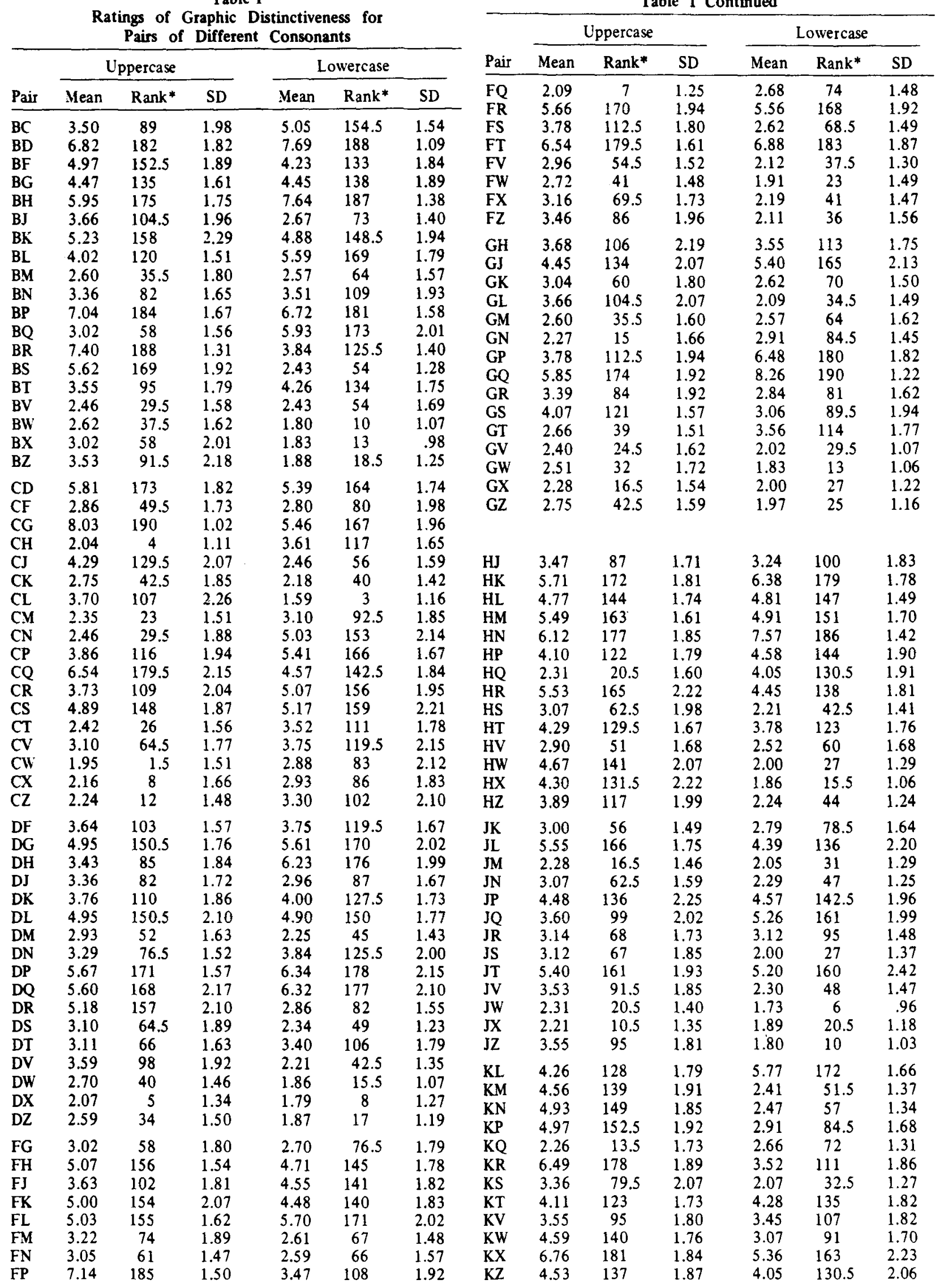

Table 1 Continued 


\begin{tabular}{|c|c|c|c|c|c|c|c|c|c|c|c|}
\hline \multirow[b]{2}{*}{ Pair } & \multicolumn{3}{|c|}{ Uppercase } & \multicolumn{3}{|c|}{ Lowercase } & & Lppercase & \multicolumn{3}{|c|}{ Lowerçase } \\
\hline & Mean & Rank* & $\mathrm{SD}$ & Mean & Rank* & SD & Mean & Rank* & Mean & Rank* & $\mathrm{SD}$ \\
\hline L.M & 3.54 & 93 & 1.60 & 2.07 & 32.5 & 1.15 & 4.38 & 2.18 & 4.98 & 152 & 1.98 \\
\hline IN & 3.83 & 115 & 1.64 & 2.64 & 71 & 1.71 & 3.95 & 118.5 & 4.45 & 138 & 2.38 \\
\hline LP & 3.49 & 88 & 1.99 & 2.79 & 78.5 & 1.68 & 4.72 & 1.98 & 5.14 & 157 & 2.33 \\
\hline LQ & 2.32 & 22 & 1.72 & 2.62 & 68.5 & 1.46 & 4.12 & & & & \\
\hline LR & 4.16 & 124 & 1.83 & 3.34 & 103.5 & 1.60 & \multirow{3}{*}{\multicolumn{5}{|c|}{$\begin{array}{l}\text { *Rank in distribution from most to least distinctive comparison } \\
N=190 \% .\end{array}$}} \\
\hline IS & 2.53 & 33 & 1.68 & 1.54 & 2 & .92 & & & & & \\
\hline LT & 5.52 & 164 & 1.64 & 5.05 & 154.5 & 2.14 & & & & & \\
\hline LV & 3.36 & 82 & 1.92 & 1.80 & 10 & 1.17 & \multirow{5}{*}{\multicolumn{5}{|c|}{$\begin{array}{l}\text { comparisons, the product-moment correlation } \\
\text { coefficient between scores on Forms I and II served as } \\
\text { the reliability estimate. In each case. reliability was } \\
\text { demonstrated to be satisfactory: } r=.90 \text { for uppercase }\end{array}$}} \\
\hline LW & 2.95 & 53 & 1.54 & 1.78 & 7 & 1.00 & & & & & \\
\hline LX & 3.23 & 75 & 1.73 & 1.69 & 4 & 1.06 & & & & & \\
\hline $\mathrm{LZ}$ & 3.82 & 114 & 2.05 & 1.93 & 24 & 1.36 & & & & & \\
\hline $\mathrm{MN}$ & 6.96 & 183 & 1.25 & 7.09 & 184 & 1.61 & & & & & \\
\hline MP & 2.62 & 37.5 & 1.50 & 2.50 & 59 & 1.45 & \multirow{9}{*}{\multicolumn{5}{|c|}{$\begin{array}{l}\text { comparisons of different letters. } 94 \text { for lowercase } \\
\text { comparisons of different letters. and } .96 \text { for } \\
\text { uppercase-lowercase comparisons of the same letters. An } \\
\text { additional estimate of reliability for the uppercase } \\
\text { comparisons of different letters was made possible by } \\
\text { the availability of an independent set of ratings (Alwitt. } \\
1973 \text { ) that appeared after completion of the present } \\
\text { study. Mean ratings were given in Alwitts study for the }\end{array}$}} \\
\hline .110 & 1.95 & 1.5 & 1.47 & 2.02 & 29.5 & 1.17 & & & & & \\
\hline$M R$ & 3.71 & 108 & 1.76 & 4.88 & 148.5 & 2.04 & & & & & \\
\hline MS & 2.84 & 47.5 & 1.97 & 3.76 & 121.5 & 1.60 & & & & & \\
\hline MT & 3.95 & 118.5 & 1.51 & 2.16 & 39 & 1.19 & & & & & \\
\hline MV & 4.80 & 146 & 1.98 & 3.03 & 88 & 1.88 & & & & & \\
\hline $\mathrm{MH}$ & 7.26 & 186 & 1.72 & 6.07 & 174.5 & 1.84 & & & & & \\
\hline MX & 4.55 & 138 & 2.12 & 3.25 & 101 & 1.99 & & & & & \\
\hline $\mathrm{MZ}$ & 4.78 & 145 & 2.22 & 3.17 & 97.5 & 1.75 & & & & & \\
\hline $\mathrm{NP}$ & 2.82 & 45.5 & 1.54 & 4.00 & 127.5 & 1.79 & \multirow{9}{*}{\multicolumn{5}{|c|}{$\begin{array}{l}\text { distinctiveness of } 12 \text { uppercase consonant-consonant } \\
\text { comparisons. The correlation between these ratings and } \\
\text { the present ratings for the same pairings was quite high, } \\
\text { rho }=95 \text {. } \\
\text { Of further interest was the degree of covariation } \\
\text { between distinctiveness as measured by the present } \\
\text { rating siale method and distinctiveness as measured by } \\
\text { Gibsonis } 11969 \text { ) feature-component svstem. Uppercase }\end{array}$}} \\
\hline NQ & 2.21 & 10.5 & 1.32 & 4.07 & 132 & 1.87 & & & & & \\
\hline NR & 4.21 & 126 & 1.88 & 6.77 & 182 & 1.45 & & & & & \\
\hline NS & 2.96 & 54.5 & 2.07 & 3.59 & 116 & 1.88 & & & & & \\
\hline $\mathrm{NT}$ & 3.20 & 72 & 1.74 & 2.69 & 75 & 1.54 & & & & & \\
\hline $\mathrm{NV}$ & 5.28 & 160 & 1.97 & 4.76 & 146 & 2.61 & & & & & \\
\hline $\mathrm{NW}$ & 6.05 & 176 & 1.88 & 3.19 & 99 & 1.81 & & & & & \\
\hline $\mathrm{NX}$ & 4.75 & 143 & 1.98 & 3.34 & 105 & 1.97 & & & & & \\
\hline$\therefore z$ & 5.59 & 167 & 2.28 & 3.10 & 92.5 & 2.11 & & & & & \\
\hline$P Q$ & 3.51 & 90 & 1.90 & 7.82 & 189 & 1.18 & & is siores were & & & nsonant \\
\hline PR & 7.91 & 189 & 1.22 & 3.82 & 124 & 1.71 & & & & he 12 & phrsical \\
\hline PS & 3.61 & 100.5 & 1.90 & 2.54 & $6 ?$ & 1.32 & of determ & He & ge un 1 & ne & cais \\
\hline PT & 4.84 & 147 & 1.91 & 3.34 & 103.5 & 1.83 & & - horizontal se & & ed co & ) shared \\
\hline PV & 2.84 & 47.5 & 1.72 & 1.90 & 22 & .97 & by that con & onant withe & f the otl & $\mathrm{co}$ & nants. A \\
\hline PW & 2.30 & 19 & 1.49 & 1.50 & 1 & .97 & is & ounted as bein & hared by & two & isonants \\
\hline PX & 2.46 & 28 & 1.83 & 1.83 & 13 & 1.20 & if it & er present in b & or abse & it in bot & h. Thus. \\
\hline $\mathrm{PZ}$ & 2.47 & 31 & 1.62 & 2.27 & 46 & 1.45 & It 11 was eit & & re con & puted f & or each \\
\hline $\mathrm{QR}$ & 2.86 & 49.5 & 1.62 & 3.06 & 895 & 1.68 & & & & & \\
\hline QS & 3.61 & 100.5 & 1.65 & 2.35 & 50 & 1.43 & & $\mathrm{Ta}$ & & & \\
\hline QT & 2.07 & 6 & 1.15 & 243 & 54 & 1.31 & Ratings & Graphic Dis & eness & Uppe & \\
\hline QV & 2.45 & 27 & 1.66 & 1.88 & 18.5 & 1.14 & Lor & Comparisor & le Same & Consonan & \\
\hline QW & 2.17 & 9 & 1.38 & 1.89 & 20.5 & 1.20 & Pair & Mean & SD & & ank \\
\hline QX & 2.29 & $\begin{array}{r}18 \\
3\end{array}$ & 1.51 & 1.72 & 5 & 1.16 & & & & & \\
\hline$Q L$ & 2.00 & 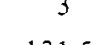 & 1.39 & 2.12 & 37.5 & 1.33 & $\mathrm{Bb}$ & 6.10 & 1.77 & & 7 \\
\hline RS & 4.30 & 131.5 & 1.89 & 3.76 & 121.5 & 2.29 & $\mathrm{Ce}$ & 8.21 & 1.44 & 1 & 7 \\
\hline RT & 4.20 & 125 & 1.59 & 5.14 & 158 & 1.99 & Dd & 3.95 & 2.13 & & 3 \\
\hline RV & 2.82 & 45.5 & 1.80 & 3.74 & 118 & 2.10 & $\mathrm{Fi}$ & 0.98 & 1.64 & 1 & 2 \\
\hline $\mathrm{RW}$ & 3.36 & 79.5 & 1.78 & 2.57 & 64 & 1.43 & $\mathrm{Gg}$ & 3.16 & 2.09 & & 1 \\
\hline $\mathrm{RX}$ & 3.57 & 97 & 2.04 & 3.58 & 115 & 2.22 & $\mathrm{Hh}$ & 5.55 & 2.09 & & 6 \\
\hline $\mathrm{RZ}$ & 3.21 & 73 & 2.03 & 3.17 & 97.5 & 2.11 & $\mathrm{Jj}_{\mathrm{j}}$ & 6.51 & 2.03 & 1 & 0 \\
\hline SI & 2.40 & 24.5 & 1.64 & 2.41 & 51.5 & 1.80 & Kk & 8.13 & 1.32 & & 3 \\
\hline SV & 2.26 & 13.5 & 1.47 & 2.70 & 76.5 & 1.86 & $\mathrm{Ll}$ & 6.55 & 1.87 & & 1 \\
\hline$S W^{\prime}$ & 2.78 & 44 & 1.67 & 3.11 & 94 & 2.23 & $\mathrm{Im}$ & 6.41 & 1.91 & & 9 \\
\hline SX & 3.16 & 69.5 & 1.98 & 3.52 & 111 & 2.16 & $\mathrm{Nn}$ & 5.08 & 2.35 & & 5 \\
\hline$S Z$ & 5.44 & 162 & 2.43 & 6.07 & 174.5 & 2.06 & $\mathrm{Pp}$ & 8.18 & 1.68 & & 5.5 \\
\hline TV & 3.30 & 78 & 1.96 & 2.53 & 61 & 1.44 & $\begin{array}{l}\mathrm{Qq} \\
\mathrm{Rr}\end{array}$ & 3.60 & 1.95 & & 2 \\
\hline$\pi w$ & 3.18 & 71 & 1.75 & 2.09 & 34.5 & 1.3 & $\begin{array}{l}\mathrm{Rr} \\
\mathrm{Sis}\end{array}$ & 4.33 & 2.27 & & 4 \\
\hline TX & 3.29 & 76.5 & 1.77 & 3.16 & 96 & & Sis & 8.18 & 1.56 & & 5.5 \\
\hline $\mathrm{TZ}$ & 4.23 & 127 & 1.92 & 48 & 58 & & $\mathrm{Tt}$ & 6,28 & 2.06 & & 8 \\
\hline & & & & & 98 & 1.34 & $V_{V}$ & 8.44 & 1.21 & - & 0 \\
\hline$\sqrt{n}$ & 7.27 & 187 & 1.48 & 7.47 & 185 & 1.1 & 116 & 8.14 & 1.52 & 1 & 4 \\
\hline $\mathrm{VX}$ & 5.25 & 159 & 2.04 & 5.28 & 162 & 1.97 & $X_{x}$ & 8.30 & 1.31 & 1 & 8 \\
\hline$V Z$ & 3.77 & 111 & 1.66 & 4.04 & 129 & 2.25 & $\mathrm{Zz}$ & 8.33 & 1.44 & 1 & 9 \\
\hline
\end{tabular}


Table 3

Correlations Between Feature-Component Scores and Mean Rating Scores for Different Letters (Uppercase)

\begin{tabular}{|c|c|c|c|c|c|c|c|}
\hline Letter & I & Letter & I & Letter & I & Letter & I \\
\hline B & $.56^{*}$ & $\mathrm{H}$ & $.46^{*}$ & $\mathbf{N}$ & .17 & $\mathbf{T}$ & $.57 *$ \\
\hline C & $.49^{*}$ & $\mathrm{~J}$ & .19 & P & $.75 \div$ & V & $.70 \div$ \\
\hline D & $.80 \div$ & $\mathrm{K}$ & $.62 \div$ & $Q$ & .21 & W & $.59 \div$ \\
\hline F & $.72 \div$ & L & $.47^{*}$ & $\mathbf{R}$ & $.61 \div$ & $X$ & $.55^{*}$ \\
\hline G & .45 & $\mathbf{M}$ & $.72 \div$ & S & .23 & Z & -.01 \\
\hline
\end{tabular}

consonant. The product-moment correlation coefficients between feature-derived and rating-derived scores for all 20 consonants are listed in Table 3 . With $17 \mathrm{dfs}, 14$ of the 20 correlations attained statistical significance.

\section{REFERENCES}

Alwitt, L. F. Relationship of visual and name similarity of visually presented letters. Memory \& Cognition, 1973, 1, 209-212.

Gibson, E. J. Principles of perceptual learning and detelopment. New York: A ppleton-Century-Crofts, 1969

Kausler, D. H.. \& Pavur, E. J., Jr. Orthographic distinctiveness of consonants and recognition learning. Journal of Experimental Psychology, in press.

Krueger, L. E. Effect of irrelevant surrounding material on speed of same.different judgments of two adjacent letters. Journal of Experimental Psychology, 1973, 98, 252-259.

Thompson, M. C., \& Massaro, D. W. Visual information and redundancy in reading. Journal of Experimental Psychology, $1973,98,49.54$.

Zechmeister, E. B. Orthographic distinctiveness. Journal of Verbal Learning \& Verbal Behavior, 1969, 8, 754-761.

(Received for publication September 18,1973 ; revision received November 30,1973 .) 